\title{
Giyilebilir Yürüyüş Analiz Sensörü ile Kişi Sınıflandırmasının Öznitelik Seçme Algoritmaları ile İyileştirilmesi
}

\author{
Abdülkadir GÜMÜŞÇÜ* \\ Elektrik-Elektronik Mühendisliği, Mühendislik Fakültesi, Harran Üniversitesi, Şanlıurfa, Türkiye \\ agumuscu@harran.edu.tr
}

(Geliş/Received: 17/04/2019;

Kabul/Accepted: 16/07/2019)

\begin{abstract}
Öz: Yürüme, canlıların bilinen en eski aktivitelerinden biridir. Konum değiştirmek amacı ile insanların kas ve kemik sistemlerinin koordineli bir şekilde hareket etmesine yürüme denir. Yürüme biyometrik bir ölçüt olarak kabul edilmektedir. Bu yüzden yürüyüş analizi ile kişi tanıma, yaş belirleme, cinsiyet belirleme, nörolojik ve ortopedik hastalık tespiti gibi çalışmalar yapılabilmektedir. Bu çalışmada da giyilebilir yürüyüş analizi sensörü ile kişilerin sınıflandırılmasında sarmal modelli öznitelik seçme yöntemleri kullanılarak daha başarılı sınıflandırma başarı parametrelerinin elde edilmesi amaçlanmıştır. 7'si bayan 9'u bay olmak üzere toplam 16 farklı gönüllü kişinin yürüyüş parametreleri hesaplanarak yürüyüş veri seti oluşturulmuştur. Her gönüllüden $3 \mathrm{kez}$ yürümeleri istenmiş olup toplam 48 yürüyüş ele alınmıştır. Kişi sınıflandırma başarı parametreleri k-en yakın komşuluk yöntemi kullanılarak hesaplanmış olup birini dışarıda bırak çapraz doğrulama yöntemi ile doğrulanmıştır. Sınıflandırma sonuçları ele alındığında 0,979 doğruluk oranı elde edilmiştir. Sonuçlar sınıflandırma başarı parametreleri ve sınıflandırma işlem süresi bakımından incelenmiş olup elde edilen sonuçlar çalışmanın sınıflandırma başarı parametreleri ve sınıflandırma işlem süresi bakımından ciddi oranda iyileştirmeler sağladığı gözlemlenmiştir.
\end{abstract}

Anahtar kelimeler: Yürüyüş analizi, sarmal modelli öznitelik seçme, sınıflandırma, kişi tanıma.

\section{Improvement of Wearable Gait Analysis Sensor based Human Classification using Feature Selection Algorithms}

\begin{abstract}
Gait is one of the oldest known activity. It is called gait in the coordinated manner of muscle and bone systems of people with the purpose of changing position. Gait is considered a biometric criterion. Therefore, studies such as human identification, age determination, gender identification, detection of neurological and orthopedic diseases can be done by gait analysis. In this study, it is aimed to obtain more successful classification success parameters by using wrapper model feature selection methods in the human classification with wearable gait analysis sensor. Gait data set was created by calculating the gait parameters of a total of 16 different volunteers including 7 female and 9 male. For each volunteer, 3 different gait parameters were calculated and a total of 48 gait were discussed. Human classification success parameters were calculated by using k-nearest neighborhood method and the results was verified by leave one out cross-validation method. When the classification results are considered, 0.979 accuracy rate was obtained. The results were examined in terms of the classification success parameters and the processing time, the results obtained showed significant improvements in the classification success parameters and the classification process time.
\end{abstract}

Key words: Gait analysis, wrapper feature selection methods, classification, human recognition.

\section{Giriş}

Yürüyüş, kas ve kemik sisteminin senkron bir şekilde hareket etmesi ile insanların konum değiştirebilmelerini sağlayan, insanlık tarihinin bilinen en eski aktiviteleri arasında sıralanmaktadır. Yürüyüş kişilerin boyu, kemik sistemi, kilosu, kas yapısı gibi birçok parametreye bağlı bir süreçtir. Bu yüzden yürüyüş de parmak izi [1, 2], göz irisi [3,4], avuç içi çizgileri [5-7] gibi biyometrik bir ölçüt olarak kabul edilmektedir. Şekil 1'de bir yürüyüş döngüsünün fazları gösterilmiştir. Şekil 1'de de görüldüğü üzere yürüyüş döngüsü fazlardan oluşmakta ve her yürüyüş fazında yürüyüş parametrelerini etkileyecek durumlar gerçekleşmektedir. Bu durum yürüme olayının kişileri ayırt edebilecek kadar çok fazla farklı parametre hesaplanabileceğini göstermektedir.

Yürüyüş analizi ile yürüyüşün o an hangi aşamada olduğu tanımlanabilir, yürüyüşün kinematik ve kinetik parametreleri belirlenebilir. Böylelikle elde edilen parametreler ile yürüyüş analizi ile kişi tanıma [9, 10], cinsiyet belirleme [11-13], yaş belirleme [14] problemleri ele alınabilmektedir. Yürüyüş parametrelerinin hesaplanmasının ardından parametreler ile kişi tanıma işlemi makine öğrenme yöntemleri tarafından yapılmaktadır [15]. Özellikle tıbbi karar verme çalışmalarında kullanılan yürüyüş veri setlerinde örnek sayısı az, nitelik sayısı oldukça fazladır

\footnotetext{
* Sorumlu yazar: agumuscu@ harran.edu.tr. Yazarın ORCID Numarası: 0000-0002-5948-595X
} 
[16]. Bu açıdan bakıldığında yürüyüş verilerini, yürüyüşs sayısının az olması ve nitelik sayısının fazla olması sebebiyle sınıflandırmak çok zordur. Bu yüzden yürüyüş analizlerinde öznitelik seçme algoritmaları çok önemli bir işlem adımıdır. Öznitelik seçme yöntemleri, niteliklerin sınıflarla ilişkisi fazla olanlarının seçilmesi ve bu nitelikler ile daha başarılı makine öğrenmesi gerçekleştirilmesini amaçlamaktadır.

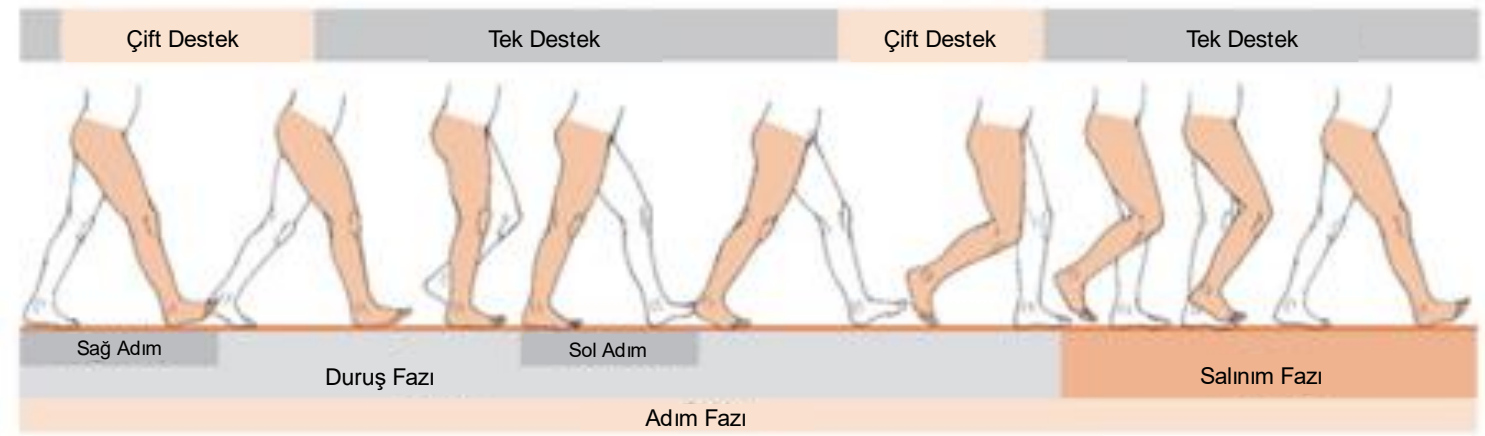

Şekil 1. Yürüyüş Döngüsü [8]

Öznitelik seçme yöntemleri, filtre [17, 18], sarmal [19] ve gömülü [20] olmak üzere üç farklı model ile ele alınmaktadır. Filtre modelli öznitelik seçme yöntemleri işlem süreleri kısa fakat başarı oranı düşüktür. Sarmal modelli öznitelik seçme yöntemleri ise başarı oranı yüksek sonuçlar vermekte fakat işlem süresi oldukça fazladır. Gömülü öznitelik seçme yöntemleri ise bağımsız bir yöntem olmayıp zaten bir sınıflandırma yönteminin içinde gömülü olarak uygulanması ile gerçekleştirilir.

$\mathrm{Bu}$ çalışmada yürüyüş analizi ile kişi tanıma için yeni bir veri seti oluşturulmuş ve oluşturulan veri setinde sınıflandırma başarı oranını iyileştirmek amacı ile sarmal modelli öznitelik seçme yöntemi uygulanmıştır. $\mathrm{Bu}$ amaçla 7 bayan 9 bay olmak üzere 16 kişinin yürüyüş verileri hesaplanmıştır. Sınıflandırma yöntemi olarak k-en yakın komşuluk yöntemi (k-NN), öznitelik seçme yöntemi olarak ise sarmal modelli öznitelik seçme yöntemi olarak meta sezgisel bir yöntem olan genetik algoritma kullanılmıştır. Sınıflandırma başarı parametreleri birini dışarıda bırak çapraz doğrulama yöntemi ile doğrulanmıştır.

Çalışmanın ikinci bölümünde yürüyüş analizi üzerine literatürde yapılmış çalı̧̧alara yer verilmiştir. Üçüncü bölümde, kullanılan veri setine ve makine öğrenme yöntemlerine değinilmiştir. Çalışmanın dördüncü bölümünde deneysel sonuçlar, beşinci bölümde ise elde edilen bulgular sunulmuştur. Son kısmında ise elde edilen sonuçlar değerlendirilmiştir.

\section{Literatür Çalışması}

Literatürde yürüyüs analizi ilgili tıbbi [21-24], toplumsal güvenlik [25, 26], spor [27] gibi birçok alanda uygulamalara rastlamak mümkündür. Tıbbi alanda yapılan yürüyüş analiz çalışmalarında, ortopedik [28] ve nörolojik $[21,22,29,30]$ hastalıkların teşhisi, tedavisi üzerine odaklanılmıştır. Toplumsal güvenlik alanında yapılan çalışmalar ele alındığında ise toplum kameraları analizi [26], şüpheli kişi tespiti [25] konularında yoğunlaşmıştır. Spor alanında ise genellikle sakatlık rehabilitasyonu [27] konularında çalışılmaktadır.

Literatürdeki çalışmalar ele alındığında yürüyüş analizlerinin giyilebilir sensör $[10,30]$ ve laboratuvar ortamlarında [31] alınan veriler ile yapıldığı görülmektedir. Giyilebilir sensör ile yapılan analizler, laboratuvar dışındaki yürüyüşleri de analiz etmeyi ve kişinin günlük aktiviteleri sırasında yürüyüş̧ü hakkında bilgi edinmeyi mümkün k1lar.

Giyilebilir sensörler ile yapılan yürüyüş analizlerinde, kişilerin ayak, diz ve bel gibi vücudun çeşitli uzuvlarına takılan sensör kullanılır. Bu sensörler jiroskop [32], akselerometre [33], kuvvet sensörleri [31], elektromiyografi [34] şeklinde sıralanabilir. Laboratuvar ortamında yapılan yürüyüş analizleri ise görüntü işleme yöntemlerini kullanan [35] ve sensörlü zemini kullanan [36] olmak üzere iki gruba ayırmak mümkündür.

Kluge ve ark. [37] diz protezi takılan hastaların ameliyat sonrasındaki yürüyüşlerin nasıl değiştiğini belirlemek amacı ile yürüyüş analiz sensörü kullanmışlardır. Yapılan çalışmada diz protezi ameliyatından sonra hastaların adım süresi ve adım uzunluğu yürüyüş parametrelerinin etkilendiği gözlemlenmiştir.

Raccagni ve ark. [38] idiyopatik ve atipik parkinson hastalarının yürüyüş analizlerini karşılaştırmış ve bu iki farklı tip parkinson hastalığının yürüyüş analizi ile birbirinden ayırt edebilmeyi amaçlamıştır. Yapılan çalışma 
sonucunda atipik parkinson hastalarının adım uzunluğu ve yürüyüş hızı parametrelerinin idiyopatik parkinson hastalarına göre oldukça düşük olduğu tespit edilmiştir.

Wang ve ark. [25] dış mekan kamera görüntülerinden silüet analizi yaparak kişileri tanımayı amaçlamışlardır. Böylelikle düşük hesaplama maliyeti ile canlı görüntülerde kişi tanıma işlemini gerçekleştirmişlerdir.

Fathima ve Banu [39] kişilerin yürüyüş sırasında ayak bileği ile ayak arasında kalan açı bilgisini kullanarak kişi tanıma problemine farklı bir yaklaşım önermişlerdir. [39]'de en iyi başarı oranı \%93,2 olarak hesaplanmıştır. Bu çalışmada oluşturulan veri seti ile kişi tanımada sınıflandırma başarı oranı ciddi oranda iyileştirilmiştir.

Souza ve Stemmer [40] Microsoft firmasının ürettiği kinetic sensörünün ürettiği görüntüler ile 10 farklı kişinin yürüyüş parametreleri hesaplamıştır. Yapılan çalışmada sekiz farklı sınıflandırma algoritması kullanılmış olup kişi tanıma sınıflandırma başarı oranı ortalama \%90,47 olarak hesaplanmıştır. Çalışmada sekiz farklı sınıflandırma yöntemi arasında en iyi sınıflandırma başarı oranı olarak \%100 başarı oranı hesaplanmıştır. Bu çalışmada ise 16 farklı kişinin yürüyüş verilerinden öznitelik seçme yapılarak yapılan kişi tanıma sınıflandırmasında \%97,92 başarı oranı sağlanmıştır. Bu iki çalışma arasında sınıf sayısı farkı gözönünde bulundurulduğunda bu çalışmada elde edilen sonuçların daha başarılı olduğu varsayılabilir.

Nieto-Hidalgo ve ark. [41] kinetic sensörlerden elde ettiği RGB görüntüleri analiz ederek yürüyüşlerin normal veya normal olmayan diye sınıflandırmışlardır. Bu çalışmada ise yürüyüşler kişi baz alınarak sınıflandırılmıştır.

Gümüşçü [10] ise yaptığı çalışmada 16 farklı kişinin yürüyüş verilerini sınıflandırmış ve \%56,25 sınıflandırma başarı oranı elde etmiştir. Bu çalışmada ise aynı veri seti kullanılarak sarmal modelli öznitelik seçme yöntemi kullanılmış olup sınıflandırma başarı oranı \% 07,92 gibi ciddi bir oranda arttırılmıştır.

Bu çalışmada ise yürüyüș verileri kullanılarak kişi tanıma işlemi sarmal modelli öznitelik seçme yöntemi ile iyileştirilerek daha başarılı bir sınıflandırma yapılması amaçlanmıştır. Bunun yanında bu çalışmada kullanılan yürüyüş veri seti diğer araştırmacılar ile internet ortamında paylaşılarak konu ile ilgili çalışma yapmak isteyen araştırmacılara destek olunması amaçlanmaktadır.

\section{Materyal ve Yöntem}

\subsection{Yürüyüş Veri Seti}

Bu çalışmada kullanılan veri seti 7'si bayan 9'u bay olmak üzere toplam 16 farklı gönüllü kişinin yürüyüş parametreleri hesaplanarak oluşturulmuştur. Gönüllü 16 kişinin yaşları 20 ile 34, ağırlıkları ise 53 ile 95 arasında değişmektedir. Her yürüyüş parametresinin hesaplanabilmesi için kişilerden Şekil 2'de detayı verilen parkuru üç tur yürümeleri istenmiştir.

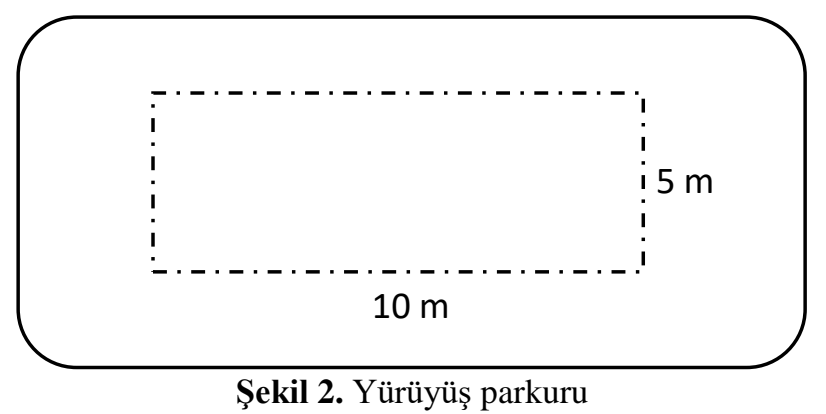

Her gönüllü Şekil 2'de verilen parkuru üç tur yürüdükten sonra ilgili yürüyüş için Tablo 1'de verilen 4 farkl1 kategoride yürüyüş nitelikleri hesaplanmıştır. Gönüllülerden bu parkuru üç kez üç tur yürümeleri istenmiştir. Dolaysıyla her kişi 3 farklı yürüyüş ile veri setinde bulunmaktadır.

Tablo 1'de verilen her nitelik için ortalama değer, medyan değer, standart sapma, çeyrekler açıklı̆̆1, oran, en küçük değer, en büyük değer ve değişim katsayısı gibi istatistiksel değerler hesaplanmaktadır. Böylelikle her üç tur yürüyüşün sonucunda 321 adet nitelik hesaplanmaktadır. Bunun yanında 16 gönüllünün üç kez üç tur yürüdüğü gözönünde bulundurulursa veri setindeki örnek sayısı 48 olacaktır. Bu haliyle bu çalışmada kullanılan veri seti 48 adet örnek 321 adet nitelikten oluşmaktadır. 
Tablo 1. Yürüyüş nitelikleri

\begin{tabular}{|c|l|l|}
\hline No & $\begin{array}{l}\text { Yürüyüş Niteliği } \\
\text { Kategorisi }\end{array}$ & \multicolumn{1}{c|}{ Nitelikler } \\
\hline 1 & $\begin{array}{l}\text { Temel } \\
\text { Parametreler }\end{array}$ & Hız, Değişkenlik, Simetri \\
\hline 2 & $\begin{array}{l}\text { Geçici } \\
\text { Parametreler }\end{array}$ & $\begin{array}{l}\text { Topuk Basma Süresi, Çevrim Süresi, Kadans, Duruş, Salınım, } \\
\text { Yükleme, Ayak Basma, İtme, Çift Destek }\end{array}$ \\
\hline 3 & $\begin{array}{l}\text { Uzaysal } \\
\text { Parametreler }\end{array}$ & $\begin{array}{l}\text { Adım Uzunluğu, Adım Hızı, Tepe Açı Hızı, Maksimum Salınım } \\
\text { Hızı, Dönme Açısı, Adım Açısı, Kaldırma Açısı, Salınım } \\
\text { Genişliği, 3D Yol Uzunluğu }\end{array}$ \\
\hline 4 & $\begin{array}{l}\text { Yükseklik } \\
\text { Parametreleri }\end{array}$ & $\begin{array}{l}\text { Maksimum Topuk Yüksekliği, Maksimum Parmak Ucu } \\
\text { Yüksekliği, Minimum Parmak Ucu Yüksekliği }\end{array}$ \\
\hline
\end{tabular}

Şekil 3'de ise yürüyüş yapan gönüllülerin fotoğrafları gösterilmiştir.
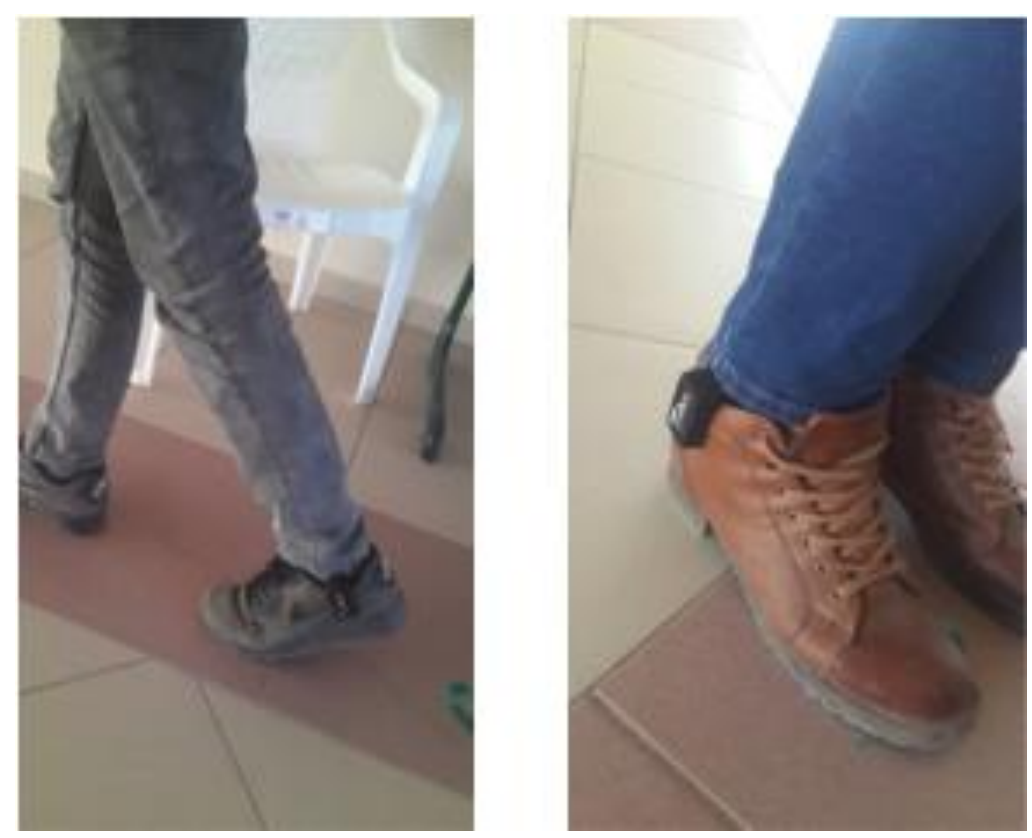

Şekil 3. Gönüllü fotoğrafları

Giyilebilir yürüyüs analiz sensörü olarak Gaitup firmasının ürettiği Physilog 5 sensörü kullanılmıştır. Bu sensör içerisinde akselerometre, jiroskop ve barometrik basınç sensörü içermektedir. Bu sensör birçok tıbbi uygulamada $[42,43]$ yürüyüş parametrelerini hesaplamak amacı ile kullanılmıştır.

\section{2. Öznitelik Seçme Yöntemleri}

Makine öğrenmesi uygulamalarında bazen örnek toplamak zaman alıcı ve masraflı bir işlem olmaktadır. Bu sebeple veri setinde örnek sayısı sınırlı elde edilmektedir. Buna karşın her örnek için de yüksek sayıda nitelik olduğu düşünüldüğünde nitelikler ile sınıflar veya sonuç değerleri arasında ilişki kurmak zorlaşmaktadır. $\mathrm{Bu}$ durumda öznitelik seçme yöntemleri kullanılarak nitelik sayısını azaltmak daha başarılı bir sınıflandırma yapmak için ideal çözümlerden bir tanesidir. Öznitelik seçme yöntemleri filtre, sarmal ve gömülü olmak üzere üçe ayrıllrr. $\mathrm{Bu}$ çalışmada sarmal modelli öznitelik seçme yöntemi olan genetik algoritma ile öznitelik seçme yöntemi kullanılmıștır. Genetik algoritma birçok alanda kullanılan meta sezgisel bir algoritmadır [44-46]. Genetik algoritma ile öznitelik seçme işleminde oluşturulan nesillerin nasıl anlamlandırıldığı Şekil 4'de gösterilmiştir. 


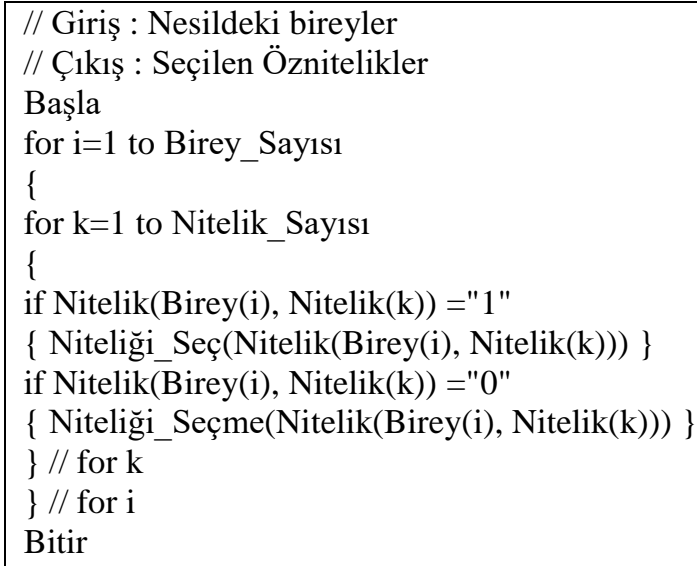

Şekil 4. Genetik Algoritma ile öznitelik seçilmesi işleminin sözde kodu

Şekil 4'de görüldüğü üzere nitelik sayısı kadar bitlik bir birey oluşturulmakta ve her bit ilgili niteliğin seçilip seçilmediğini belirtmektedir.

\section{3. k-NN Sınıflandırma Yöntemi}

k-NN sınıflandırma yöntemi kullanım kolaylığı, anlaşılabilirliği ve büyük verilerdeki kararlığı sebebiyle bir çok sınıflandırma işleminde sıklıkla kullanılmaktadır [47]. k-NN yöntemi bellek tabanlı bir sınıflandırma yöntemidir. Eğitim aşamasında kullanılan örnekler sınıf bilgisi ile düzleme yerleştirilir. Test aşamasında ise sınıf tahmini yapılacak olan örnek için düzlemdeki diğer k adet en yakın komşusuna ele alınır. En fazla hangi sınıfa ait en yakın komşusu var ise örnek için o sınıfa ait olduğuna karar verilir. Bu çalışmada uzaklık ölçütü olarak öklid uzaklık ölçütü seçilmiştir. Eşitlik 1'de D boyutlu bir uzayda öklid uzaklık ölçütü formülize edilmiştir [48].

$$
d(A, B)=\left(\sum_{i=1}^{D}\left|a_{i}(x)-a_{i}(y)\right|^{2}\right)^{1 / 2}
$$

Eşitlik 1'de $a_{i}(x)$ her öznitelik için belirlenen x noktasının i'ninci boyutundaki sayısal değeri ifade eder. $a_{i}(y)$ ise yine her öznitelik için belirlenen y noktasının i'ninci boyutundaki sayısal değeri ifade eder. Ayrıca çalışmada $\mathrm{k}$ değeri 1 olarak alınmıştır. 3,5,7 gibi farklı k değerlerinde denemeler yapılmış olup k değerinin değişiminin sınıflandırma başarı parametrelerine çok ciddi etki etmediği gözlemlenmiştir.

\section{Deneysel Çalışmalar}

$\mathrm{Bu}$ çalışmada oluşturulan veri setinde yürüyüş verileri ile kişiler Şekil 5'de verilen işlem adımları ile sınıflandırılmıştır.

Şekil 5'de görüldüğü üzere yürüyüş veri seti için ilk olarak başlangıç nesli oluşturulmaktadır. Bu nesil daha sonra seçme, mutasyon gibi genetik operatörlere tabii tutularak yeni ve farklı nesillerin oluşturulması sağlanmıştır. $\mathrm{Bu}$ aşamada genetik algoritma için her nesildeki birey sayıs 200 , çaprazlama oranı 0,8 , mutasyon oranı 0,1 olarak belirlenmiştir. Oluşturulan yeni nesildeki bireyler k-NN sınıflandırma yöntemi ile sınıflandırılarak sınıflandırma başarı parametreleri hesaplanmaktadır. k-NN sınıflandırma yöntemi için k değeri 1 olarak belirlenmiştir. Elde edilen sınıflandırma başarı oranının \%100'e ulaşması veya nesil limitine ulaşılması durumda yöntem sonlandırılarak sınıflandırma işlemi tamamlanmaktadır. Nesil limiti 100 olarak belirlenmiştir. Çalışmada kişileri yürüyüş verilerine göre sınıflandırma başarısını değerlendirmek doğruluk, özgüllük, duyarlılık, hassasiyet ve f-1 ölçütü parametreleri kullanılmıştır. Eşitlik 2-6'de parametreler ifade edilmiştir [49].

$$
\begin{gathered}
\text { Doğruluk }=\frac{T P+T N}{T P+T N+F P+F N} \\
\text { Özgüllük }=\frac{T N}{F P+T N} \\
\text { Duyarlılık }=\frac{T P}{T P+F N} \\
\text { Hassasiyet }=\frac{T P}{T P+F P}
\end{gathered}
$$




$$
F 1 \text { Ölçütü }=\frac{2 . T P}{2 T P+F P+F N}
$$

2,3,4,5 ve 6 nolu denklemlerde verilen (TP) A kişi olarak tahmin edilen A kişi sayısını; (FP) A kişi olarak sınıflandırılan A'dan farklı kişi sayısını; (FN) A kişisinden farklı olup A kişi olarak sınıflandırılan kişi sayısını; (TN) ise A kişisinden farklı olup A kişisinden farklı olarak sınıflandırılan kişi sayısı olarak ifade edilmiştir. Hesaplamalar, $2.8 \mathrm{GHz}$ frekansa sahip Intel Core i7 işlemci, $8 \mathrm{~GB}$ RAM bulunan bir bilgisayarda gerçekleştirilmiştir. Bunun yanında sınıflandırmada elde edilen başarı parametreleri birini dışarıda bırak çapraz doğrulama yöntemi ile doğrulanmıştır.

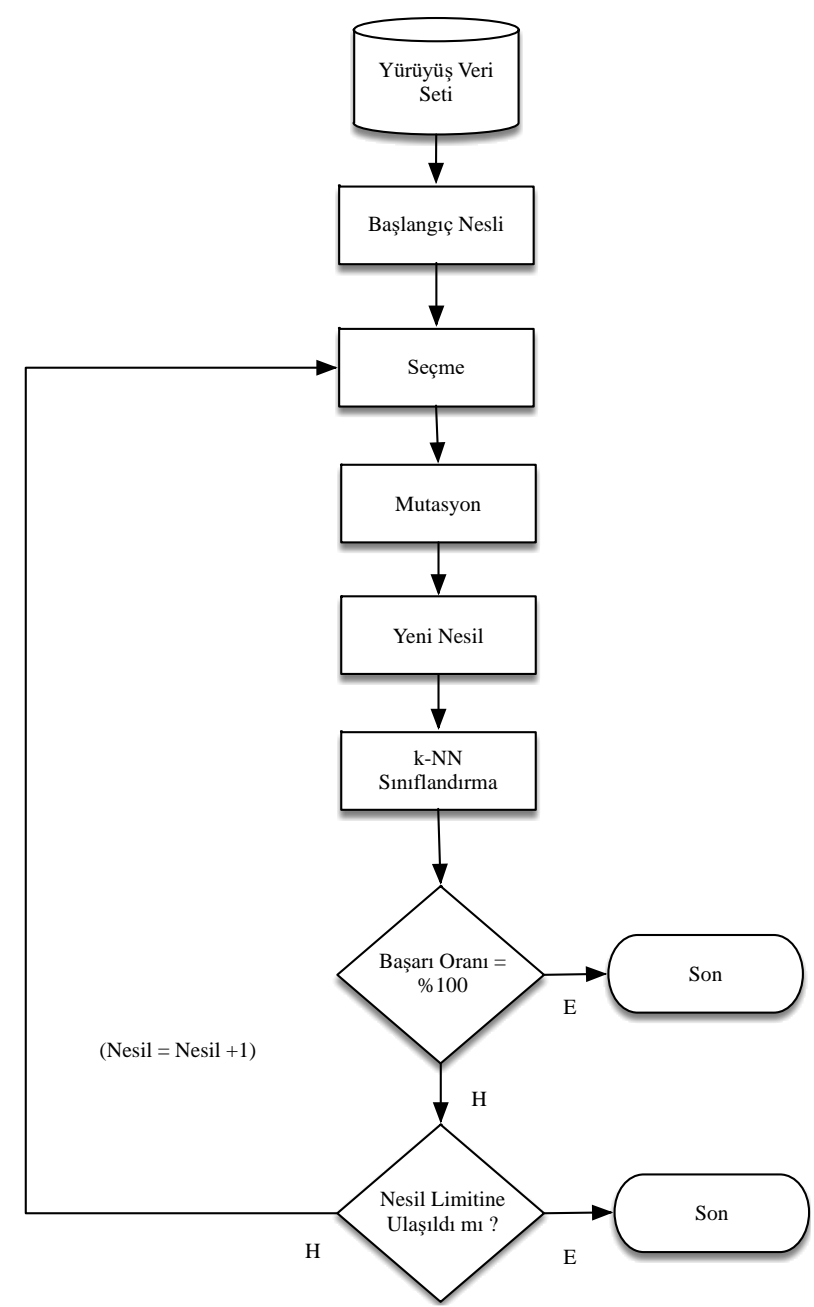

Şekil 5. Uygulanan akışşeması

\section{Bulgular ve Tartışma}

$\mathrm{Bu}$ çalışmada giyilebilir yürüyüş analiz sensörü ile kişiler k-NN yöntemi sınıflandırılmıştır. Elde edilen sonuçlar [10] çalışması ile karşılaştırılıp öznitelik seçme yöntemlerinin etkisi gözlemlenmiştir. Tablo 2'de elde edilen sınıflandırma başarı parametreleri verilmiştir.

Tablo 2. Başarı parametreleri

\begin{tabular}{|c|c|c|c|c|c|}
\hline Sinıflandırma Yöntemi & Doğruluk & Özgüllük & Duyarlılık & Hassasiyet & F1-Ölçütü \\
\hline$[10]$ nolu çalışma & 0,562 & 0,615 & 0,333 & 0,166 & 0,221 \\
\hline GA - k-NN & 0,979 & 1,000 & 0,977 & 0,750 & 0,848 \\
\hline
\end{tabular}


Tablo 2'deki sonuçlar ele alındığında uygulanan öznitelik seçme yönteminin başarı parametreleri üzerinde ciddi iyileştirmeler sağladığı görülmektedir. Tablo 3 'de ise yöntemlerin süre bakımından karşılaştırması yapılmıştır.

Tablo 3. İșlem süreleri

\begin{tabular}{|c|c|c|c|}
\hline Sınıflandırma Yöntemi & $\begin{array}{c}\text { Öznitelik Seçme } \\
\text { Süresi }\end{array}$ & $\begin{array}{c}\text { Sınıflandırma } \\
\text { süresi }\end{array}$ & $\begin{array}{c}\text { Toplam } \\
\text { Süre }\end{array}$ \\
\hline$[10]$ nolu çalışma & - & $1,846 \mathrm{~s}$ & $1,846 \mathrm{~s}$ \\
\hline GA - k-NN & $4769,5 \mathrm{~s}$ & $0,830 \mathrm{~s}$ & $4770,4 \mathrm{~s}$ \\
\hline
\end{tabular}

Tablo 3'deki verilen sonuçlar, sarmal modelli öznitelik seçme yönteminin sınıflandırmanın yapılma süresini azalttığını göstermektedir. Kişi tanıma uygulamalarında özniteliklerin bir kez seçildiği göz önünde bulundurulduğunda azalan nitelik sayısı ile beraber sürenin kısaltılabildiği gözlemlenmiştir. Bunun yanında genetik algoritma ile öznitelik seçme işlemi sonucunda 147 adet öznitelik seçilmiştir. Şekil 6'da ise genetik algoritma ile öznitelik seçme işleminin nesillere göre hata oranını nasıl değiştirdiği gösterilmektedir.

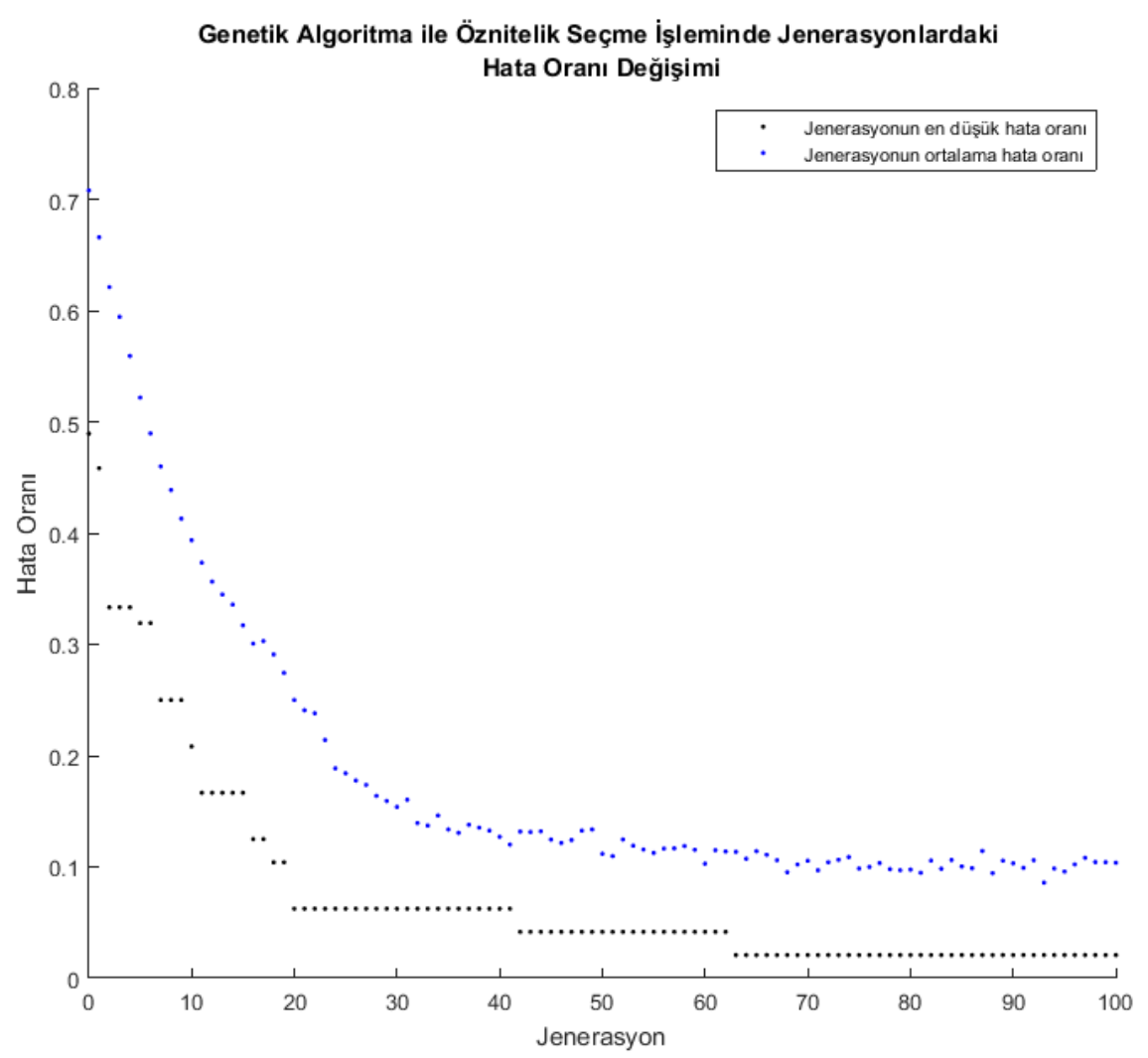

Şekil 6. Hata oranının genetik algoritma ile iyileştirilmesi

Şekil 6'da da görüldüğü üzere genetik algoritma ile öznitelik seçme işlemi başara parametrelerine ciddi katkılar sağlamıştır. İlk nesildeki hata oranı yaklaşık 0,70 iken son nesilde yaklaşık 0,02 değerine kadar düşmüştür.

\section{Sonuçlar}

$\mathrm{Bu}$ çalışmada giyilebilir yürüyüş analiz sensörleri ile kişi tanıma uygulamalarında öznitelik seçme yöntemlerinin etkisi ele alınmıştır. Öznitelik seçme yöntemi olarak genetik algoritma ile sarmal modelli öznitelik seçme yöntemi kullanılmıştır. Bunun yanında yürüyüş niteliklerine göre kişileri sınıflandırmak için k-NN 
sınıflandırma yöntemi kullanılmıştır. Sınıflandırma işlemi ile kişiler birbirinden 0.979 doğruluk oranı ile ayırt edilebilmiştir.

Elde edilen sonuçlar ele alındığında [10] nolu çalışma ile aynı yürüyüş veri seti kullanıldığından yapılan karşılaştırmalara göre öznitelik seçme yöntemi başarı parametrelerine oldukça ciddi iyileștirmeler sağlamıştır. Tablo 2'de verilen sonuçlar incelendiğinde öznitelik seçme yöntemi ile doğruluk oranı 0,417 gibi ciddi bir artış göstermiştir. Bu durumda veri setinde bulunan 321 adet nitelik içerisindeki bazı niteliklerin sınıf etiketi ile korelasyonu bozduğu ve hata oranını yükselttiği sonucuna varılabilir. Bunun yanında öznitelik seçme yapılması ile beraber f1-ölçütü 0,627 kadar artmıştır.

İşlem süreleri bakımından bulgular ele alındığında öznitelik seçme yöntemi sarmal modelli olduğundan işlemin uzun sürmesi beklenen bir sonuç olarak karşımıza çıkmıştır. Bunun yanında yürüyüş analizi ile kişi tanıma uygulamasında öznitelik seçme işleminin bir kez çalıştırılıp sınıf etiketi ile korelasyonu yüksek nitelikler belirlendikten sonra yapılacak olan sınıflandırma işlemlerinde daha kısa süre sınıflandırma işlemi yapılabilecektir. Böylelikle daha hızlı bir sınıflandırma uygulaması gerçekleștirilebilecektir.

Şekil 6'da verilen nesillere göre ortalama hata oranı ve en düşük hata oranı grafiği öznitelik seçme işleminin gerekliliğini göstermektedir. Öznitelik seçme yöntemi ile beşinci nesildeki bile ilk nesile göre hata oranı yaklaşık 0,400 iyileştirilmiş̧ir. Bu da öznitelik seçme işleminin hızı bir şekilde sınıflandırma başarı parametrelerini iyileştirdiğini göstermektedir.

\section{Teşekkür}

$\mathrm{Bu}$ çalışma, Harran Üniversitesi Bilimsel Araştırma Kurulu tarafından 17004 numaralı proje ile desteklenmektedir.

\section{Kaynaklar}

[1] Yager N, Amin A. Fingerprint classification: a review. Pattern Analysis and Applications 2004; 7(1): 77-93.

[2] Hong L, Wan YF, Jain A. Fingerprint image enhancement: Algorithm and performance evaluation. Ieee Transactions on Pattern Analysis and Machine Intelligence 1998; 20(8): 777-789.

[3] Ma L, Tan TN, Wang YH, Zhang DX. Efficient iris recognition by characterizing key local variations. Ieee Transactions on Image Processing 2004; 133(6): 739-750.

[4] Wildes RP. Iris recognition: An emerging biometric technology. Proceedings of the ieee 1997; 85(9): 1348-1363.

[5] Lee JC. A novel biometric system based on palm vein image. Pattern Recognition Letters 2012; 33(12): 1520-1528.

[6] Wang HG, Yau WY, Suwandy A, Sung E. Person recognition by fusing palmprint and palm vein images based on "Laplacianpalm" representation. Pattern Recognition 2008; 41(5): 1514-1527.

[7] Zhou YB, Kumar A. Human Identification Using Palm-Vein Images. Ieee Transactions on Information Forensics and Security 2011; 6(4): 1259-1274.

[8] Oatis C. Kinesiology: The mechanics and pathomechanics of human movement. Second edition. 2013.

[9] Arivazhagan S, Induja P. Gait Recognition-Based Human Identification and Gender Classification. Proceedings of International Conference on Computer Vision and Image Processing; 2017; pp. 533-544.

[10] Gümüşçü A. Wearable Sensor based Gait Recognition for Human Identification. in International Conference on Multidisciplinary, Science, Engineering and Technology; 25 -27 October 2018; Dubai, United Arab Emirates. pp. 31-33.

[11] Ahmed MH, Sabir AT. Human Gender Classification based on Gait Features using Kinect Sensor. 3rd Ieee International Conference on Cybernetics (Cybconf); 2017; pp. 243-247.

[12] Borras R, Lapedriza A, Igual L. Depth Information in Human Gait Analysis: An Experimental Study on Gender Recognition. Image Analysis and Recognition. 2012; 7325: 98-105.

[13] Lu JW, Wang G, Moulin P. Human Identity and Gender Recognition From Gait Sequences With Arbitrary Walking Directions. Ieee Transactions on Information Forensics and Security 2014; 9(1): 51-61.

[14] Lu JW, Tan YP. Gait-Based Human Age Estimation. Ieee Transactions on Information Forensics and Security 2010; 5(4): 761-770.

[15] Bulut F, Amasyalı MF. Locally adaptive k parameter selection for nearest neighbor classifier: one nearest cluster. Pattern Analysis and Applications 2017; 20(2): 415 - 425.

[16] Schena M, Shalon D, Davis R, Brown P. Quantitative Monitoring of Gene Expression Patterns With a Complementary DNA Microarray. 1995, pp. 467-70.

[17] Yvan Saeys II, Larrañaga P. A review of feature selection techniques in bioinformatics. Bioinformatics 2007; (23)19: 2507-2517.

[18] Çelik C, Bilge HŞ. Ağırlıklandırılmış Koşullu Karşılıklı Bilgi İle Öznitelik Seçimi. Journal of the Faculty of Engineering and Architecture of Gazi University 2015; 30(4).

[19] Gumuscu A, Karadag K, Tenekeci M, Aydilek I. Genetic algorithm based feature selection on diagnosis of Parkinson disease via vocal analysis. 2017 25th Signal Processing and Communications Applications Conference (SIU). 2017.

[20] Quinlan JR. C4.5: programs for machine learning. San Francisco, CA, USA: Morgan Kaufmann Publishers Inc, 1993. 
[21] Abdulhay E, Arunkumar N, Narasimhan K, Vellaiappan E, Venkatraman V. Gait and tremor investigation using machine learning techniques for the diagnosis of Parkinson disease. Future Generation Computer Systems. 2018;83:366373.

[22] Aich S, Choi K, Pradhan P, Park J, Kim H. A Performance Comparison Based on Machine Learning Approaches to Distinguish Parkinson's Disease from Alzheimer Disease Using Spatiotemporal Gait signals. Advanced Science Letters. 2018;24(3):2058-2062.

[23] Amboni M, Cozzolino A, Longo K, Picillo M, Barone P. Freezing of gait and executive functions in patients with Parkinson's disease. Movement Disorders. 2008;23(3):395-400.

[24] Boutaayamou M, Demonceau M, Bruls O, Verly JG, Garraux G. Analysis of temporal gait features extracted from accelerometer-based signals during ambulatory walking in Parkinson's disease. Movement Disorders. 2016;31.

[25] Liang Wang, Tieniu Tan, Huazhong Ning, Weiming Hu. Silhouette analysis-based gait recognition for human identification. IEEE Trans Pattern Anal Mach Intell. 2003;25(12):1505-1518.

[26] Zhang D, Wang YH. Gender Recognition Based on Fusion of Face and Multi-view Gait. in Advances in Biometrics vol. 5558, Tistarelli M, Nixon MS. Lecture Notes in Computer Science, 2009, pp. 1010-1018.

[27] Christensen J, LaStayo P, Marcus R et al. Visual knee-kinetic biofeedback technique normalizes gait abnormalities during high-demand mobility after total knee arthroplasty. Knee. 2018;25(1):73-82.

[28] McNair P, Boocock M, Dominick N, Kelly R, Farrington B, Young S. A Comparison of Walking Gait Following Mechanical and Kinematic Alignment in Total Knee Joint Replacement. J Arthroplasty. 2018;33(2):560-564.

[29] Aharonson V, Schlesinger I, McDonald A, Dubowsky S, Korczyn A. A Practical Measurement of Parkinson's Patients Gait Using Simple Walker-Based Motion Sensing and Data Analysis. J Med Device. 2018;12(1):011012.

[30] Haji Ghassemi N, Hannink J, Martindale C et al. Segmentation of Gait Sequences in Sensor-Based Movement Analysis: A Comparison of Methods in Parkinson's Disease. Sensors. 2018;18(2):145.

[31] Kidziński Ł, Delp S, Schwartz M. Automatic real-time gait event detection in children using deep neural networks. PLoS ONE. 2019;14(1):e0211466.

[32] Mileti I, Germanotta M, Di Sipio E et al. Measuring Gait Quality in Parkinson's Disease through Real-Time Gait Phase Recognition. Sensors. 2018;18(3):919.

[33] Samà A, Rodríguez-Martín D, Pérez-López C et al. Determining the optimal features in freezing of gait detection through a single waist accelerometer in home environments. Pattern Recognit Lett. 2018;105:135-143.

[34] Ziegier J, Gattringer H, Mueller A. Classification of Gait Phases Based on Bilateral EMG Data Using Support Vector Machines. 2018 7th IEEE International Conference on Biomedical Robotics and Biomechatronics (Biorob). 2018.

[35] Rocha AP et al. Parkinson's Disease Assessment Based on Gait Analysis Using an Innovative RGB-D Camera System. in 2014 36th Annual International Conference of the Ieee Engineering in Medicine and Biology Society, IEEE Engineering in Medicine and Biology Society Conference Proceedings. 2014; pp. 3126-3129.

[36] Meurisse G, Dierick F, Schepens B, Bastien G. Determination of the vertical ground reaction forces acting upon individual limbs during healthy and clinical gait. Gait Posture. 2016;43:245-250.

[37] Kluge F, Hannink J, Pasluosta C et al. Pre-operative sensor-based gait parameters predict functional outcome after total knee arthroplasty. Gait Posture. 2018;66:194-200

[38] Raccagni C, Gaßner H, Eschlboeck S et al. Sensor-based gait analysis in atypical parkinsonian disorders. Brain Behav. 2018;8(6):e00977.

[39] Sithi Shameem Fathima SMH, Wahida Banu RSD. Abnormal walk identification for systems using gait patterns. 2016, pp. 112-117.

[40] Souza AM, Stemmer M. Extraction and Classification of Human Body Parameters for Gait Analysis. 2018.

[41] Nieto-Hidalgo M, Ferrández-Pastor F, Valdivieso-Sarabia R, Mora-Pascual J, García-Chamizo J. A vision based proposal for classification of normal and abnormal gait using RGB camera. J Biomed Inform. 2016;63:82-89.

[42] Mariani B. Assessment of Foot Signature Using Wearable Sensors for Clinical Gait Analysis and Real-Time Activity Recognition. EPFL.

[43] Brégou Bourgeois A, Mariani B, Aminian K, Zambelli P, Newman C. Spatio-temporal gait analysis in children with cerebral palsy using, foot-worn inertial sensors. Gait Posture. 2014;39(1):436-442. doi:10.1016/j.gaitpost.2013.08.029

[44] Holland J. Genetic Algorithms. Sci Am. 1992;267(1):66-72.

[45] Gümüşçü A, Tenekeci M, Bilgili A. Estimation of wheat planting date using machine learning algorithms based on available climate data. Sustainable Computing: Informatics and Systems. 2019. doi:10.1016/j.suscom.2019.01.010

[46] Gümüşçü A, Tenekeci M, Tabanlıŏlu A. The shortest path detection for unmanned aerial vehicles via genetic algorithm on aerial imaging of agricultural lands. International Advanced Researches and Engineering Journal. 2018;2(3): 315319.

[47] Jeon H, Lee W, Park H et al. Automatic Classification of Tremor Severity in Parkinson's Disease Using a Wearable Device. Sensors. 2017;17(9):2067. doi:10.3390/s17092067

[48] Bulut F. A new clinical decision support system with instance based ensemble classifiers. Journal Of The Faculty Of Engineering And Architecture Of Gazi University 2017;32(1):65-76.

[49] Bulut F. Çok Katmanlı Algılayıcılar İle Doğru Meslek Tercihi. Anadolu Üniversitesi Bilim Ve Teknoloji Dergisi AUygulamalı Bilimler ve Mühendislik 2016;17(1):97-109. 